\title{
THE IMPACT OF RISK OF POVERTY ON SEGMENTS OF THE MARKET IN ROMANIA
}

\author{
Marcela-Cornelia Danu \\ “Vasile Alecsandri” University of Bacău \\ marceladanu@ub.ro
}

\begin{abstract}
In the present work I presented the risk of poverty in Romania considering the economic and social determination. I highlighted that poverty in Romania, is a mix of economic, educational, cultural etc. factors and reinforced by the lack of family or social support. Among the most significant correlative causes of poverty are: lack of money-unemployment, low salaries, lack of money, lack of food-hunger, deprivation, misery, lack of culture, lack of housing, disease, decay, addictions, political causes, individual causes, etc. I analyzed the dynamics of the decision-making behavior of the population of Romania both as a whole and as segments of the market, in terms of age, sex, residence environment, etc. in the market acts, regarding the purchase and consumption decision. The approach and treatment of the poverty must be understand regarding to the systemic economic-social-psychologically interaction. The impact of risk of poverty on the segments of the market is reflected in the production of goods and services; increasing of this type of risk lead to diminishing and modifying the request and further lead to diminishing supply, business failure, etc.
\end{abstract}

\section{Keywords}

risk of poverty; segments of the market; unemployment; consumer behaviour; consumption; consumption expenditure

\section{JEL Classification}

E21; E24; F15; I32; J19

\section{Premises and levels of poverty in Europe}

The economic and financial global crisis, starting in the third quarter of 2007, he made his presence felt on the European continent during the year 2008. The impact of the crisis has been severe, manifesting itself over the entire societal system; the economic, social, political, natural, psychological etc. dimensions were affected each one in different shapes and sizes, resulting the negative effects with mutual determination and interdependences spread in time and space. Although the European economy has exceeded the phases of crisis and economic recession, the statistical data shows that by the end of 2013, this "refitting", yet, is in a slow pace [Sustainable development in the European Union, http://epp.eurostat.ec.europa.eu/].

The premises of the risk of poverty in different sizes and level of gravity are, in reality, the forms of economic and financial crisis, like this:

- lack of credit and asset price drop;

- decrease of the demand of consumers;

- $\quad$ increasing the savings of household;

- $\quad$ lowering the investment of firms and households;

- decreased international trade;

- $\quad$ decreased of GDP/capita;

- $\quad$ the raising government debt; 
and men;

- drop the level of the employment, principally in the case of young people

- $\quad$ the reduction in labour productivity;

- $\quad$ drop the level of industrial production in response to diminishing demand.

Increasing the level of unemployment and long-term unemployment, having economic, social and psychological impact on those who are in this situation.

At EU level, as a whole, the risk of poverty has fallen even if the premises were not favorable; for the age groups 18-24 years and 25-49 years, the risk of poverty has slightly increased. The intensity of poverty has increased, more for the segment of the male population and for the middle-aged persons. The decrease in financial potential of the private donors has determined the decrease in financial support of the aid to those affected by poverty.

If during the 2005 - 2008 the risk of poverty has fallen, since 2008 the risk of poverty has affected more and more persons, so that in the 2012 have been exposed to the risk of poverty or social exclusion with 8.7 million people more than in 2008. In absolute figures, in the 2008 the number of people exposed to the risk of poverty was 115.7 million and during the 2012 - 124,4 million (approx. 25\% of the population of EU). Against the background of the crisis and the economic recession, the poverty in general, monetary poverty in the main, those severe materials deficiencies, lack of jobs - have marked the economic, social and personal life and last but not least the psychic balance so much desirable, of a large part of the european population.

It is considered that "the current levels of poverty and social exclusion endanger the objective of Europe 2020 strategy of the eradication of poverty, which is intended to reduce by at least 20 million number persons confronted with the risk of poverty and social exclusion by 2020".

The monetary poverty is the main form of poverty in the EU. In the 2012, this affect $17.1 \%$ of the total population of EU. Of total number of those affected by poverty, in the 2012, a significant number of 85.3 million people, has been affected by a risk of monetary poverty. The situation is worrisome because it highlights an increase of 5.7 $\%$ compared to the 2008. What's more, this indicator has increased almost continuously from the 2005, therefore, before the economic and financial global crisis comes, and his evolution was accelerated after the 2009.

Another form of manifestation of poverty is the material privations. If in the previous period of crisis, respectiv between the 2005-2008, the number of affected people with severe materials privations in the EU decreased by approx. 12 million, in the 2012 approx. 51 million people were affected by this "disease" $(10.3 \%$ of the EU population), their number increasing during the 2008-2012 with $23.18 \%$.

Regarding to the income inequality, during the 2005-2012, it has recorded small changes. In 2012, the richest $20 \%$ of the EU population were revenue representing more than $38 \%$ of national income/adult equivalent, respective 5 times more than the poorest $20 \%$ of EU population (their weightings being approx. $8 \%$ of the population).

The labour market in the EU is still marked by instability, from this point of view sustainability being placed in uncertainty. In 2012, the number of people living in household with very low work intensity was 36.9 million (9.8\% of the EU population in the ages of 0 and 59 years), growing up with $7.58 \%$ from 2008. The economic inactivity is a significant premise of risk of poverty.

The unemployment is a determinant key of economic and social health of the population. In EU, between the 2004-2008, the long-term unemployment rate had a downward trend. Beginning to 2008, the rate has risen again, in 2012, reaching peak of 4.6 percent.

Although the gender disparities have been mitigated during the 2006-2011, the gross earnings per hour carried out of women were in 2011, with $16.2 \%$ lower than those of men. 


\section{Coordinates of the risk of poverty in Romania}

In a national environment affected by the transition toward a market economy, and more recently, by the transition toward the economic and financial crisis, the risk of poverty has reached in our country the highest levels, after Bulgaria. Although the crisis manifested at the large scale in Romania too, the dynamic of the number of people exposed to the risk of poverty was relatively favorable (tab.1), the share of the exposed persons have fallen from $45.9 \%$ in 2007 to $41.7 \%$ in 2012 [www.eurostat.com, 15.06.14]; however, the size of the weighting of persons exposed to this type of risk is a reason for concern in so far as, the segments of the young population - under 18 years (52.2 \% in 2012) respective $18-24$ years (45.6 \% in 2012) are the most affected.

Table 1 People at risk of poverty or social exclusion by age, in Romania (\%)

\begin{tabular}{|c|c|c|c|c|c|c|}
\hline Years & $\mathbf{2 0 0 7}$ & $\mathbf{2 0 0 8}$ & $\mathbf{2 0 0 9}$ & $\mathbf{2 0 1 0}$ & $\mathbf{2 0 1 1}$ & $\mathbf{2 0 1 2}$ \\
\hline Total & 45.9 & 44.2 & 43.1 & 41.4 & 40.3 & 41.7 \\
\hline Less than 18 years & 50.5 & 51.2 & 52.0 & 48.7 & 49.1 & 52.2 \\
\hline From 18 to 24 years & 43.3 & 44.2 & 42.7 & 42.1 & 44.4 & 45.6 \\
\hline From 25 to 49 years & 39.2 & 38.5 & 38.3 & 37.8 & 37.8 & 38.5 \\
\hline From 50 to 64 years & 47.2 & 44.0 & 43.6 & 42.3 & 38.5 & 40.8 \\
\hline 65 years or over & 57.7 & 49.2 & 43.1 & 39.9 & 35.3 & 35.7 \\
\hline
\end{tabular}

Source: Processed by www.eurostat.com, 15.06.14

By analysing a risk of poverty on the basis of the age and sex, we notice that in the preceding year of the crisis in Romania, 2007, the share of poor women it was greater than that of the men; it is also interesting that the share of the men who were poor, in all the segments of the age of less than 50 years, it has been higher than the share of the women from the same segments of the age; instead, for the segments for more than 50 years, the women held the highest weightings of exposure to poverty.

In 2012, the last year of the analysis, the situation on the segments of the age has become more difficult for the segment of women than for the segment of men, they predominantly to the almost all the segments of the age with the exception of segment 18-24 years (fig.1,2).

An important criterion in studying the impact of risk of poverty on the behavior of the consumption of individuals is their employment situation (tab.2). From this point of view, of all the segments of the age employed, the most exposed at the risk of poverty is the segment of the young people between the ages 18 and 24; the situation got worse, so that, if in the $2007,42.3 \%$ of the young employees were exposed to the risk of poverty, in 2012 the share increased by more than 10\%. For other segments of the age, possible employee, the situation has sensitive improved. 


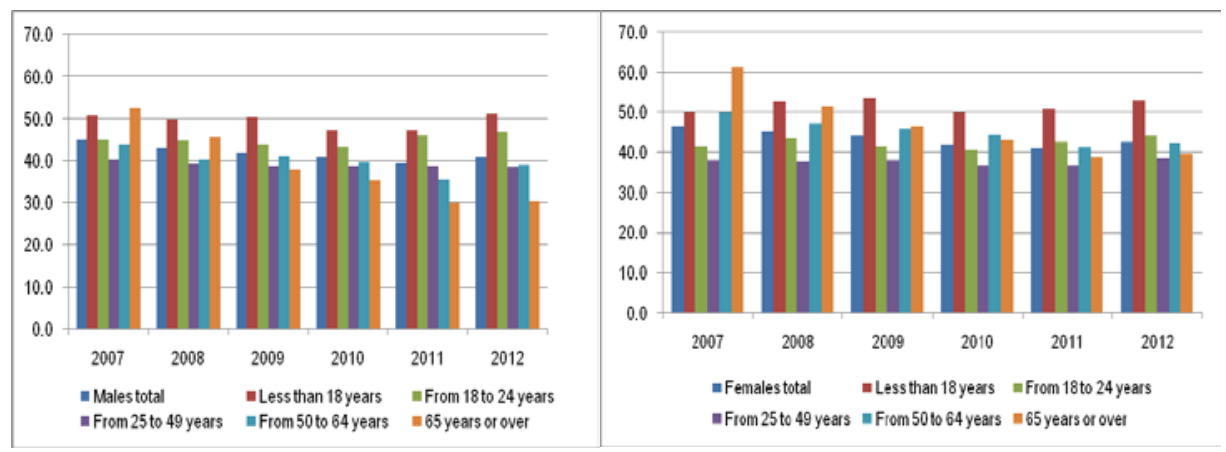

Figure $1 \& 2$ People at risk of poverty or social exclusion by sex and age, in Romania (\%)

Source: Processed by www.eurostat.com, 15.06.14

Table 2 People at risk of poverty or social exclusion by status and age employed persons, in Romania (\%)

\begin{tabular}{|c|c|c|c|c|c|c|}
\hline Status and age & $\mathbf{2 0 0 7}$ & $\mathbf{2 0 0 8}$ & $\mathbf{2 0 0 9}$ & $\mathbf{2 0 1 0}$ & $\mathbf{2 0 1 1}$ & $\mathbf{2 0 1 2}$ \\
\hline Employed persons from 18 to 24 years & 42.3 & 49.3 & 48.8 & 45.6 & 52.8 & 52.7 \\
\hline Employed persons from 25 to 49 years & 32.7 & 32.1 & 32.6 & 32.1 & 32.3 & 32.2 \\
\hline Employed persons from 50 to 64 years & 35.4 & 34.3 & 34.3 & 33.9 & 31.4 & 33.7 \\
\hline Employed persons 65 years or over & 73.1 & 60.0 & 47.9 & 55.4 & 57.6 & 47.6 \\
\hline
\end{tabular}

Source: Processed by www.eurostat.com, 15.06.14

Taking into account all the criteria referred to, respective age, sex, persons employed, during the 2007-2012 (fig.3.,4), we notice that the employed men in the segment 1824 years have recorded a deterioration of the economic situation, the exposure to the risk of poverty increasing far beyond the 2010. For the segment of the age 25-49, in the entire period of the analyzed time, the exposure to the risk of poverty has been greater for male, employee segment. The segment of the age 50-64, employed persons, is more affected by this risk in case of the women, but the trend was declining throughout the period. The segment of over 65 years is less significant from this point of view of the employment possibility, recording in the case of men a downward trend of the weighting of those affected, and, in the case of women, after an increase in crisis period, a decrease from the 2011.

Although the situation of poverty is very difficult for the entire society, regardless of which would be the segment of the market, this has a great dimension due the negative propagated effects, in the case of persons not employed. In this situation, the principal cause of the poverty in general, of the monetary poverty and material deprivation, in particular, it is the unemployment. For the persons not employed, the exposure to the risk of unemployment is equivalent, for the most part, with exposure to a risk of poverty. The greatest exposure to the risk of poverty was registered in 2007 in the case of the 25-49 years old but very high weights are for the all segments of the population (tab.3). It is significant that although the crisis has affected all the 
economic entities, this type of risk decreased in the case of unemployed by the year
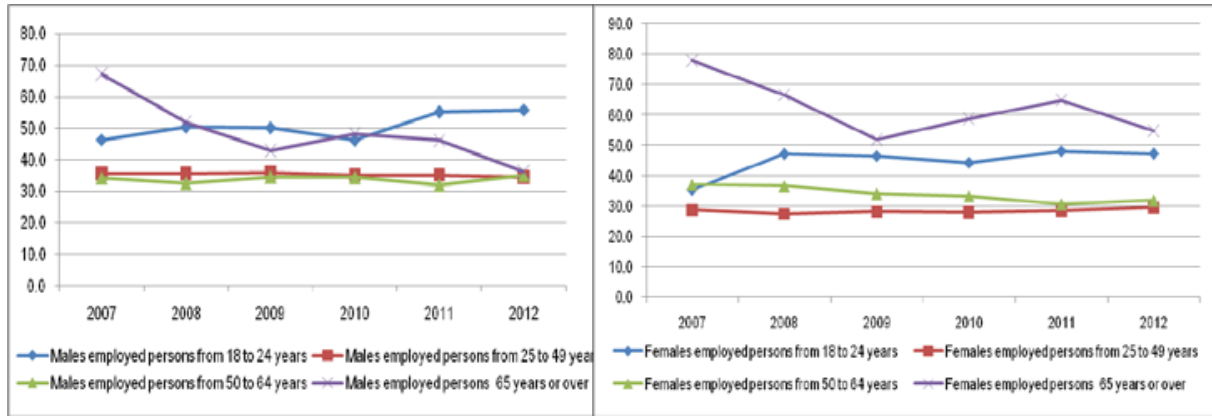

2011, increasing again in 2012, but not to the levels of 2007.

Figure 3 \& 4 People at risk of poverty or social exclusion by status, sex and age employed persons, in Romania (\%)

Source: Processed by www.eurostat.com, 15.06.14

The only segment of the population whose exposure to the risk of poverty has increased in 2012 compared with 2007 is the specific to the fullness period in an individual's active life, respective $25-49$, from $64.3 \%$ to $65.9 \%$.

Table 3 People at risk of poverty or social exclusion by status and age - not employed persons, in Romania (\%)

\begin{tabular}{|c|c|c|c|c|c|c|}
\hline Status and age & $\mathbf{2 0 0 7}$ & $\mathbf{2 0 0 8}$ & $\mathbf{2 0 0 9}$ & $\mathbf{2 0 1 0}$ & $\mathbf{2 0 1 1}$ & $\mathbf{2 0 1 2}$ \\
\hline Not employed persons from 18 to 24 years & 43.9 & 40.6 & 39.0 & 39.7 & 40.7 & 43.3 \\
\hline Not employed persons from 25 to 49 years & 64.3 & 63.0 & 61.8 & 61.5 & 60.9 & 65.9 \\
\hline Not employed persons from 50 to 64 years & 55.5 & 51.4 & 50.4 & 49.2 & 44.7 & 47.4 \\
\hline Not employed persons 65 years or over & 56.2 & 48.4 & 42.9 & 39.3 & 34.5 & 35.1 \\
\hline
\end{tabular}

Source: www.eurostat.com, 15.06.14

Taking into account, at the same time, the criterion: occupational-status unemployed, sex and age, we noted (fig.5.,6):

- the most exposed at risk of poverty are, for the whole analized time, the unemployed people, men, in the 25-49 years segments, closely followed by the women of the same age segment;

- a vulnerable segment of age to this type of risk is the one between 50 and 64 years old, the most vulnerable in the case of the unemployed women and less vulnerable in the case of the unemployed men;

- $\quad$ both the men and the women from young people segment (18-24 years old) are in large proportion, over $40 \%$ of the young population, exposed to the risk of poverty but in less proportion than the segments of age referred to;

- $\quad$ the segment of over the 65 years age, not employed is the most exposed to this risk, regardless of gender of person. From the economic, social, psychological point of view it is important to the persons in this situation but reduced size of this segment of population given retirement from economic life of most people after 65 years, it does not create the great problems of the macroeconomic scale.

Another criterion of the segmentation of the market is the degree of urbanization. Statistical data show that the exposure to the risk of poverty is the most "powerful" in 
the case of persons residing in areas with low population density. In our country, in the 2007, 56\% of the population resident in human settlements with low density was affected by this risk; the dynamic of this indicator has been declining up to the year 2011 and increased again in 2012 (tab.4).
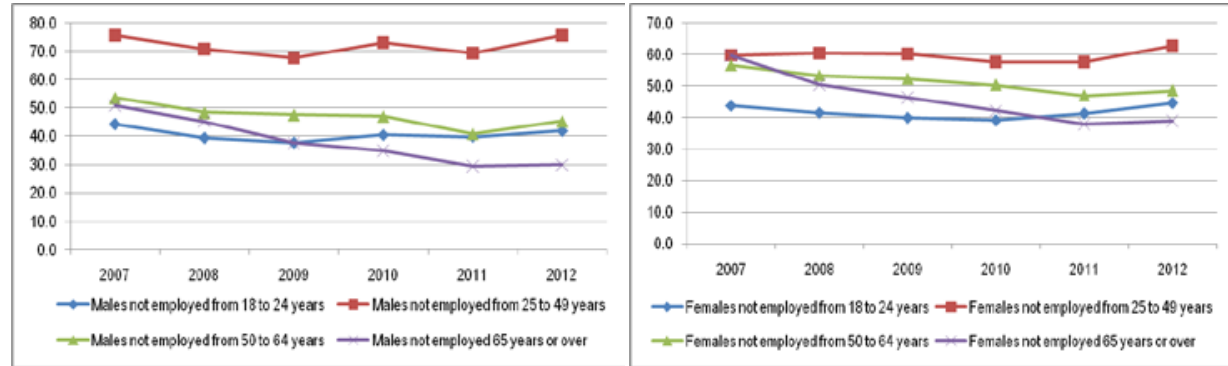

Figure $5 \& 6$. People at risk of poverty or social exclusion by status, sex and age not employed persons, in Romania (\%)

Source: Processed by www.eurostat.com, 15.06.14

A high risk of poverty has occurred in the 2007, in the case of persons residing in places with medium density (55\%), significantly reducing up to the 2012 , at $35,7 \%$. The lowest values of this type of risk are specific to the resident population in localities with high density and the concentration of the population. The reason: accessibility of workplaces, commercial areas, multiple and diversified choices.

Table 4 People at risk of poverty or social exclusion by degree of urbanisation, in Romania (\%)

\begin{tabular}{|c|c|c|c|c|c|c|}
\hline Degree of urbanisation & $\mathbf{2 0 0 7}$ & $\mathbf{2 0 0 8}$ & $\mathbf{2 0 0 9}$ & $\mathbf{2 0 1 0}$ & $\mathbf{2 0 1 1}$ & $\mathbf{2 0 1 2}$ \\
\hline Densely-populated area & 29.6 & 28.9 & 29.8 & 29.4 & 28.4 & 29.5 \\
\hline Intermediate urbanised area & 55.0 & 43.2 & 35.4 & 35.9 & 39.5 & 35.7 \\
\hline Thinly-populated area & 56.0 & 53.6 & 51.1 & 48.7 & 47.4 & 54.8 \\
\hline
\end{tabular}

Source: www.eurostat.com, 15.06.14

The poverty is one of the contemporary Romanian economy problems as a result of types of produced risk (system of risks) during this time or having the lost premises in the history of this places and to the people from this space. The psychological dimension of the poverty is not one to ignore, on the contrary; both from the causal point of view as well as that effects. The cultural coordinates of individuals, the fundamental values - respect for work, honesty, involvement, devotion and desire to take risks, always searching the formula of life who brings the material satisfaction and fulfillment spiritual - are notable to counteract the risk of poverty. An important role has, however, the quality of the national business environment - economic, social, legislative, political - by the macroeconomic policies initiated and implemented in each stage of the development of the economy. By cohabitation of the two sizes - endogenous, personal and exogenous (national, international) - the risk of poverty can be reduced, as far as possible, or heal with the economic policies and social protection policies. 


\section{The effects of poverty on consumption in Romania}

Due to increasing of the macroeconomic instability, the decrease in the level of income, purchasing power, etc. the economic crisis manifested in Romania has left deep traces in a large part of the country's population, decreasing the standard of living, its quality of life. Even now at the 8 years from the accession of Romania to the EU, the economic and social disparities persists and spreads over the entire economic system. Diminishing the purchasing power of the population, installation of poverty for a significant part of the population, poverty of youth, the unemployment and the problems generated by it, life carried on the edge of subsistence for the majority of the rural population, the material deprivations of pensioners etc. have changed the consumption patterns resulting in reduced of the products and services demand for the population, reduction of supply.

The reality reflects that the average of the consumption expenditure of the Romanians are comparable, within the EU, only with those of the Bulgarians (Stanciu, 2010). The comparisons between the consumption basket of Romanians and other European shows both the poor content of this as well as the very large gaps between the Romanians and the other Europeans, in the consumption of goods and services for health, education, culture, entertainment, etc.

In the economic crisis years, the options of the consumers - at least those which reflect more intense the subjective stimuli act of consumption have been obviously affected, due to the socio-economic barriers. It was noted that as a general rule, in the most prosperous years, most consistent segments of consumers will be able to exercise more freely the power options, the economic pressure may be low but in the last few years most of the population of Romania "understand the socio-economic restrictions imposed on more intense".

The pattern of national average consumption recorded the deviations of the values of its analytical indicators, in relation to the normal propensity for consumption of the population adopting certain pattern of consumption. These deviations were manifested not only in the consumption of food goods but also at the level of compulsory payments (tax) or utilities costs. Consumer behavior of the population was folded on the objective conditions of life of household and depending on macroeconomic policies.

The main trends and phenomena in the past 20 years, from this point of view, were the following (Stanciu, 2010):

- polarization of the acces of population to goods and services consumption; in the 1990s, Romania took the last place in Europe in terms of acces of the majority of population to necessary goods and services for a decent life;

- the population belonging to VII-X deciles of income, showed a consumist type behavior, with extreme emphases during of economic growth since the year 2000;

- national consumption pattern has recorded the highest weights of the consumption expenditure in terms of food consumption;

- the main characteristics of the national consumption model derived, for the most part, the behavior of households of employees, but also of that of the households centred on the agricultural activities, total or partially.

The situation has not fundamentally changed in recent years marked by the economic crisis. By analysing the 3 segments of the population, during the 2007-2011, reflected in segments of consumer at the level of the Romanian market respective unemployed persons, farmers, pensioners, I found that:

- the monetary expenses of the segment of unemployed persons have evolved on a increasing trend, from 1154.5 lei/ month/ household at 1631.34 lei/ month/ household (fig.7); 
- the total consumption expenditure of the segment of unemployed persons have had a positive dynamic, increasing from 931.84 lei/ month/ households at 1310.60 lei/ month/ household (fig.7);

- $\quad$ in the composition of the expenditure of consumption, food goods exceed, in all the years of analysis, $45 \%$ of the total consumption, to which is added approx. $8 \%$ concerned of the consumption of alcoholic beverages and tobacco, all these by highlighting the extremely low standard of living (fig.8);

- the expenditure for housing service, utilities, etc. occupy the following position recording a consistency increase in the last years, reflecting the concern about this segment of the population to ensure not only the survival but also the safety of home;

- the expenditure on clothing and footwear recorded the largest decrease signifying the low concern of the segment of unemployed for clothing and image;

- the transport and communication expenditure have not seen a downward trend but were placed at approx. $5 \%$ of consumption of this segment;

- the expenditure on education are very low in all the years, $0.7 \%$ in 2011 , reflecting a significant barrier in training young people from these household.
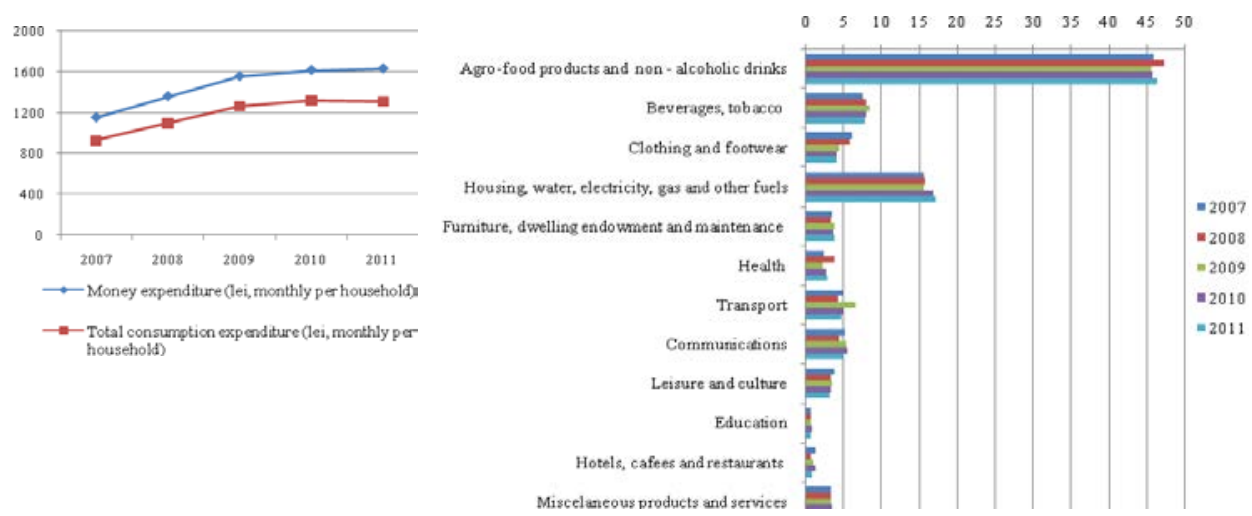

Figure 7 \& 8 Dynamic of the expenditure - case of unemployed, in Romania lei/ \%

Source: Processed by www.insse.ro

Notable for the identification of the behaviour consumer to those exposed to the risk of poverty, is the segment of farmers. In this situation, during the 2007-2011, the financial expenditure have had an increasing trend, from 1228.89 lei/ month/ household to 2002,3 lei/ month/ household much surpassing the financial situation very precarious of the unemployed persons (fig.9). Total consumption expenditure of farmers have seen a significant increase, with $50.28 \%$, from 779.4 lei at 1171.32 lei. In the composition of expenditure of consumption (fig.10), the food expenditure decreased from $56.5 \%$ to $54.4 \%$ to which is added $9 \%$ respective $9.4 \%$ expenditure on alcoholic beverages and tobacco; these expenditure have the largest weights in the total consumption compared with other segments of consumers and illustrates the precariously character of the life of the majority population of the rural roumanian environment, mainly. A small proportion hold the expenditure on clothing, down from $5.8 \%$ to $4.9 \%$ and the housing maintenance and furniture expenditure $3.2 \%$ in 2011. The percentage $1.8 \%$ of total consumption allocated in 2011 , to health and $0.2 \%$ allocated to education confirms the lifestyle remained at the level of the basic needs of the individual and very large discrepancies compared with the developed countries of the EU. 
The segment of pensioners had, as well as other segments of the population, a trend of increasing the monetary expenditure, from $1170.31 / \mathrm{month} /$ household to 1805.36 lei/ month/ household (with 54.26\%) (fig. 11).

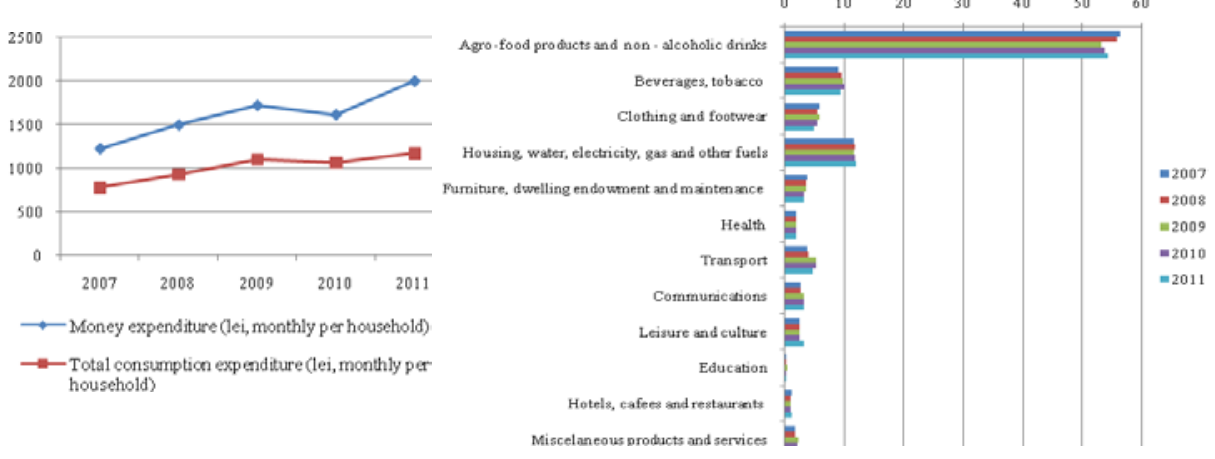

Figure $9 \& 10$. Dynamic of the expenditure - case of farmers, in Romania lei/ \%

Source: Processed by www.insse.ro
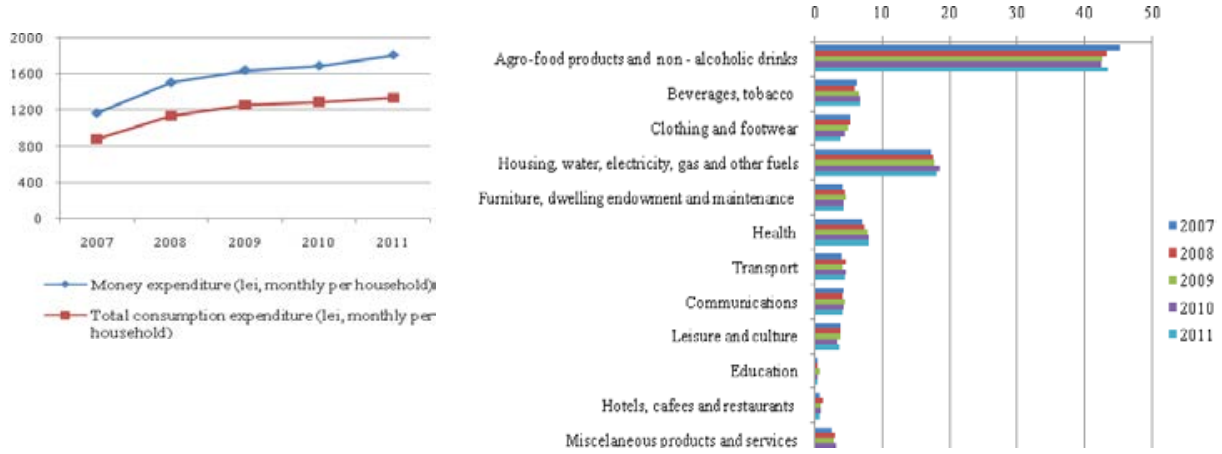

Figure 11 \& 12. Dynamic of the expenditure - case of pensioners, in Romania lei/ \%

Source: Processed by www.insse.ro

The total consumption expenditures have increased from 880.99 lei to 1330.71 lei (51.04\%) highlighting increasing prices on products in the consumer basket. In the structure of the consumption (fig.12), prevails, as in other cases affected by the risk of poverty, food expenditure, totaling, in 2011, 49.9\%. The expenditure on housing, water, electricity, gas and other fuels occupies a high, much higher percent than the other segments presented in this paper, respective $17.1 \%$ in $2007,17.9 \%$ in 2011 . The concern for the strict needs of housing but also the discipline of payment of the utilities are the main reasons of the weights in the structure of consumption. A significant share compared to other segments of the population, occupy the health expenditure, $8 \%$ in 2011, justified by the age specific issues. As in other cases, the expenditure for cultural services, education, communications, etc. dealing with small or very small weights, declining in the years marked by crisis.

By analysing the situation of the three segments of consumers exposed at risk of poverty, we notice at least one conclusion: the high consumption of food goods, 
determined both by the model of consumption, quantity and the high price levels. In our country, the pattern of food consumption of the population is characterised by (Stanciu, 2010):

- relatively high weighted of the food expenditure in total expenditure of consumption, due to the relatively high of prices of food;

- relatively high weighted of the food consumption of agricultural production of their own households (reduced marketing of the rural economy);

- $\quad$ an excessive consumption of cereals and potatoes - food with relatively low nutrient potential and an increased risk for the emergence of diabetes, under stress intense;

- $\quad$ an excessive consumption of alcohol, tobacco and fats, having the negative effects such as: incidence of diseases such as cancer, cardio-vascular diseases, tuberculosis and diseases of nutrities; alcoholism causes serious psycho-social problems;

- $\quad$ at least $2.5 \%$ of the population of the country is suffering from malnutrition chronic;

- the relatively low presence of the indigenous ecological markets in the formation of daily food basket of households. Over the last years, people of Romania has allotted approximately half of the expenditure of consumption in foods - more than half, in the very difficult economic years $55.8 \%$ in 2001), and between $45-50 \%$ in the most prosperous years, by placing our country among the European countries with a strong tension pattern of consumption at the level of consumption of the various chapters of the expenditure, primarily caused the food chapter.

\section{Conclusions}

The economic and financial contemporary crisis has deepened the problem of poverty and multiplied both the causes and its effects. Some and others interferes in the EU system and, further, in the system of world economy. Therefore, the poverty, is not only a point problem, with the point resolutions. Furthermore, the causes are not only economic but combined economic, social, political, social, psychological, naturals. Always, however, prevailing the economic nature of poverty but causes and its effects too. It is a European problem, unfortunately developed once to the crisis, and no solution yet. In Romania, the poverty reflect not only a precarious economic and social situation of those in question but also the discrepancies between social segments of the society level, the discrepancies deeping by the economic and social policies insufficient folded on Romanian reality, on the national culture, and especially on the natural, human, spiritual potential of the country.

\section{References}

Constantin, M., Alecu, I. (2012), Cheltuielile și consumurile alimentare din România, Revista Română de Statistică Trim. I/2012 - Supliment.

European Commission (2013), European social statistics, 2013 edition available at www.eurostat.com.

European Commission, Sustainable development in the European Union, available at http://epp.eurostat.ec.europa.eu/.

Intitutul National de statistica, Anuarul statistic 2012, available at http://www.insse.ro/cms/ro/content/anuarul-statistic-2012, 2011. 
Stanciu, M. (coord) (2010), Consumul populației din România, Editura Omnia UNI SAST, Brașov. 